\title{
A Probabilistic Internal Rate of Return: Theory and Illustration
}

\author{
Samih Antoine Azar ${ }^{1} \&$ Nazim Noueihed ${ }^{2}$ \\ ${ }^{1}$ Faculty of Business Administration \& Economics, Haigazian University, Lebanon \\ ${ }^{2}$ Department of Mathematics, Division of Mathematical Sciences, Faculty of Arts \& Sciences, Haigazian \\ University, Lebanon \\ Correspondence: Samih Antoine Azar, Professor, Faculty of Business Administration \& Economics, Haigazian \\ University, Mexique Street, Kantari, Beirut, Lebanon. Tel: 96-1134-9230. E-mail: samih.azar@haigazian.edu.lb
}

Received: January 12, 2014

Accepted: January 28, $2014 \quad$ Online Published: February 21, 2014

doi:10.5539/ijbm.v9n3p138

URL: http://dx.doi.org/10.5539/ijbm.v9n3p138

\begin{abstract}
The purpose of this paper is to provide a theoretical background on the internal rate of return (IRR), on the probabilistic IRR, and to present an illustration based upon both a Taylor series expansion and a Monte Carlo simulation. It is shown that Monte Carlo simulation results in a more precise outcome as compared to the theoretical expectations from a Taylor series expansion. This precision is more than twice in terms of the standard deviations of the IRR, and around six times more in terms of the standard errors of the IRR. Second, the distributions of the internal rate of return follow approximately a normal distribution, and this allows a sound basis for project appraisal and risk management. Third, the grand means of the internal rates of returns for all four cases considered are statistically insignificantly different from each other, as expected, and they are statistically insignificantly different from the average internal rate of return, obtained by discounting the mean amounts of the cash flows. Fifth, the standard deviations and the standard errors of the IRR are directly proportional to the assumed standard deviations of the cash flows.
\end{abstract}

Keywords: finance, investment analysis, uncertain cash flows, annuities, internal rate of return (IRR), probability distribution of IRR

\section{Introduction}

The purpose of this paper is to demonstrate the benefits of undertaking Monte Carlo simulation in the estimation of the probability distribution of the internal rate of return (IRR) of a project for which future cash flows are stochastic but independent. Illustrative examples are provided for four cases. The first is when future cash flows follow a uniform distribution, which is a usual assumption in the literature (Sarper et al., 2010). The second is when future cash flows follow a normal distribution with the same mean and variance as the above uniform distribution. The third is when future cash flows follow a normal distribution with the same mean as above but with double the variance. The fourth is when future cash flows follow a normal distribution with the same mean as above but with half the variance. Assuming normal distributions conforms also to the literature (Hillier, 1963; Fairley \& Jacoby, 1975; Kim \& Reinschmidt, 2012). In all cases the initial cash outlay is fixed in value. Ten thousand simulation runs are produced for each case, and these are repeated a hundred times.

It is shown that Monte Carlo simulation results in a more precise outcome, i.e. provides a lower variance for the distribution of the internal rate of return relative to the theoretical expectations from a Taylor series expansion. This precision is more than twice in terms of standard deviations and more than four times in terms of variance. In turn, the precisions of the standard errors of the IRR are around six times more precise in terms of standard deviations, and around thirty six times more precise in terms of variances. Second, the distributions of the internal rate of return follow approximately a normal distribution, together with other statistics from the simulations, and this provides for a sound basis for project appraisal and risk management. Third, the grand means of the internal rates of returns, for all four cases considered, are statistically insignificantly different from each other, as expected. Fourth, the grand means are statistically insignificantly different from the average internal rate of return, obtained by discounting the means of the cash flows. Fifth, the variances of the IRR are directly proportional to the assumed variances of the future cash flows. Finally, the squares of the standard errors of the IRR are directly proportional to the assumed variances of the future cash flows.

The paper is organized as follows. In section 2 the literature on the internal rate of return is rehearsed from its 
origins till recently. In section 3 the pitfalls of the internal rate of return are enumerated, discussed, and dismissed, especially because the IRR criterion is so popular with managers. In section 4 the illustrative model is presented together with the derivation of the expected theoretical values for the standard deviation and for the standard error of the IRR. Section 5 analyzes and summarizes the Monte Carlo simulations. The last section concludes.

\section{The Literature}

The idea behind the IRR goes back to Keynes (1953), who called the IRR the marginal efficiency of capital. He writes: "More precisely, I define the marginal efficiency of capital as being equal to that rate of discount which would make the present value of the series of annuities given by the returns expected from the capital-asset during its life just equal to its supply price" (p. 135). Some authors, like Altshuler and Magni (2012), maintain that Fisher (1930) is the earliest reference to the IRR. However this fact is disputed by Alchian (1955). Among the most active original proponents of the IRR is Dean (1954). He writes about the IRR: "The positive superiorities of a rate-of-return measure of investment worth are imposing" (p. 25). In addition Dean expresses his surprise that the yield-to-maturity, and for that purpose the yield-to-call, which both are essentially variants of the IRR, are accepted and frequently used by professionals and academicians whereas the IRR is a less familiar method to appraise investment proposals (p. 30). Dean summarizes the IRR criterion: compare the IRR of a project with the hurdle rate, the discount rate that measures the opportunity cost of funds, adjusted for the riskiness of the project. If the IRR is higher than this hurdle rate the project should be accepted, otherwise this project should be rejected. Lorie and Savage (1955) agree with Dean that "the rate-of-return method is the most defensible method heretofore proposed in the business literature for maximizing corporate profits and net worth." In their treatment of capital rationing Lorie and Savage (1955) recommend the usage of the IRR and hold the view that some of the discrepancies of the IRR, particularly the existence of multiple IRRs and ranking conflicts with the Net Present Value rule, are "undoubtedly of small practical significance." The NPV is obtained by finding out the present value, at a discount rate $R$, of all current and future net cash flows $x_{i}$ for period $i$ and that for the whole useful life of the project $N$ :

$$
N P V=\sum_{i=0}^{N} \frac{x_{i}}{(1+R)^{i}}
$$

And the IRR is the rate $r$, with $-1<r<+\infty$, that drives the NPV to zero:

$$
0=\sum_{i=0}^{N} \frac{x_{i}}{(1+r)^{i}}
$$

The discussion so far centered about the calculation of a single figure for the IRR, and comparing it to the hurdle rate. Finding a probability distribution for the IRR is the next topic. Hertz (1964) was among the first to introduce the concept of a probabilistic IRR obtained through Monte Carlo simulation. Hillier $(1963 ; 1965)$ proposed a method to find the probability distribution of the IRR from the probability distribution of the Net Present Value (NPV). Kim and Reinschmidt (2012) correctly recognize that Hillier's method requires a prior judgment about the lower and upper bounds of the potential IRR. Anyway, Hillier's method starts by calculating the expected NPV and the variance of the NPV for the cash flows from period 0 until the end of the useful life of the project $N$ at the lower bound of the IRR. Suppose this lower bound is denoted $r$. Then:

$$
\text { Probabilty }(I R R<r)=\operatorname{Probability}(N P V<0 \mid r)=\Phi\left(\frac{0-E(N P V \mid r)}{\sqrt{\text { Variance }(N P V \mid r)}}\right)
$$

In equation (3) $E(N P V \mid r)$ is the net present value of the expected values of the cash flows $\left(x_{i}\right)$ at time $i$, discounted at the rate $r$ :

$$
E(N P V \mid r)=\sum_{i=0}^{N}\left(\frac{E\left(x_{i}\right)}{(1+r)^{i}}\right)
$$

$\Phi$ is the cumulative standard normal distribution, and Variance $(N P V \mid r)$ is defined as follows: 


$$
\operatorname{Variance}(N P V \mid r)=\sum_{i=0}^{N} \sum_{j=0}^{N} \frac{\sqrt{\text { Variance }\left(x_{i}\right) \operatorname{Variance}\left(x_{j}\right)}}{(1+r)^{i+j}} \rho_{i j}
$$

In equation (5) $\rho_{i j}$ is the correlation coefficient between net cash flow $x_{i}$ and net cash flow $x_{j}$. Equation (5) simplifies to the following equation if $\rho_{i j}=0$ for all $i$ and $j$, i.e. when net cash flows are independent or uncorrelated:

$$
\operatorname{Variance}(N P V \mid r)=\sum_{i=0}^{N}\left(\frac{\operatorname{Variance}\left(x_{i}\right)}{(1+r)^{2 i}}\right)
$$

All the above relations are repeated for another, higher, value of $r$, with the expected value and the variance of the NPV calculated again at this new level of $r$, and so sequentially until a cumulative probability distribution of the IRR is obtained. Since the decision-maker is interested in the complement of the probability in equation (3), in order to compare projects, then:

$$
\text { Probability }(\operatorname{IRR}>r)=1-\text { Probability }(\operatorname{IRR}<r)
$$

This probability permits determining the feasibility of an investment as defined by Carmichael and Balatbat (2008). Hillier's methodology is still regarded as pioneering till the present as Sarper et al. (2012) recognize. Moreover, by virtue of the central limit theorem the distribution of the expected NPV in equation (4) should approach a normal distribution for increasing $\mathrm{N}$, irrespective of the actual probability distributions of the cash flows. This adds more value to Hillier's procedure. However with the advent of developed spreadsheets, like Excel, the calculation of the IRR becomes much easier.

Among the authors who try to derive analytically the frequency distribution of the IRR, Fairley and Jacoby (1975) stand out as the earliest. They study the case of cash flows described by multivariate normal distributions and are able to approximate the distribution of the IRR when variances of period costs and returns are small. A useful review of the literature on probabilistic cash flow analysis is carried out by Carmichael and Balatbat (2008) who find that the research directly related to the subject of the probabilistic IRR is scant. However, more recently Sarper et al. (2010) report closed-form probability distributions for the IRR for one-period and two-period capital budgets for which the cash flows are characterized by either uniform or exponential distributions. They note that, although one and two period capital budgets are rare, the task becomes much more difficult for budgets with a higher useful life.

\section{The IRR and Its Detractors}

The NPV and the IRR "are regarded as theoretically sound and sophisticated methods for making capital budgeting decisions" (Jog \& Srivastava, 1995, p. 37). However the IRR has come under focus by academicians because of its many "pitfalls." The purpose of this section is to discuss and refute these concerns.

It is said that the IRR method does not differentiate between investing, or lending, and borrowing (Brealey, Myers, \& Allen, 2014; Ross et al., 2010). In case of borrowing the NPV increases with an increasing discount rate, and the rule becomes to accept projects with an IRR less, and not more, than the hurdle rate. This criticism does not stand because normally the decision-maker knows in advance, by the nature of the project, whether this project is a lending or a borrowing project.

The IRR rule is considered to be inferior to the NPV rule because multiple IRRs may arise. "By Descartes's "rule of signs" there can be as many solutions to a polynomial as there are changes of signs" (Brealey, Myers, \& Allen, 2014, p. 114). However the question arises as to how frequent projects, with net cash flows changing signs, are. In typical investments this problem does not come about. In addition, "multiple relevant (i.e., real and positive) IRR values either do not exist or exist under economic assumptions that are nearly impractical" (Moshe \& Kroll, 2012, p. 101-102).

The NPV and the IRR rules may conflict in the ranking of projects. This is a related concept to the scale problem and to the timing problem (Ross et al., 2010). When comparing two projects the problem is that their NPV profiles intersect at the crossover rate. It may happen that below this rate one of the two projects is selected while above this rate the other project is selected. The solution lies with computing the incremental IRR, i.e. calculate the IRR for the differential cash flows of the two investments under scrutiny.

The IRR assumes that intermediate cash flows are reinvested at the IRR rate, a rate that is claimed to be a high rate that cannot be sustained easily. This has been called the reinvestment problem. To counter this argument 
one should note that bond valuation, which depends on the yield-to-maturity, and the yield-to-call, uses one equivalent form of the application of the IRR. In addition this problem does not arise if the IRR turns out to be low. The claim that the IRR is always high is not founded.

Finally it is claimed that the IRR does not take into consideration the term structure of interest rates (Brealey, Myers, \& Allen, 2014), while the NPV can accommodate different rates for different net cash flows by discounting each periodic net cash flow at the zero-coupon rate that corresponds to the timing of each net cash flow. However, zero-coupon rates, adjusted for the riskiness of the project, are hard to find, and the discounting proves to become very complex as the useful life of the project increases, and this complication may prove to be fruitless considering other uncertainties in the project.

All these assumed pitfalls cannot conceal the reality that most managers prefer the IRR to the NPV. See Schall et al. (1978) for US firms and Jog and Srivastava (1995) for Canadian companies. Claiming that management is irrational because of its preference is not sensible. For all practical purposes the IRR remains a valid rule. As Moshe and Kroll (2012, p. 101) write: "The popularity of IRR indicates that under reasonable practical assumptions the deficiencies of IRR relative to NPV are minor or extremely rare."

Moreover the discussion so far has considered the IRR in isolation. In fact, and particularly in this paper, the IRR methodology is supplemented by providing a probability distribution for the IRR. This will enable the decision-maker to compute probabilities for given outcomes and to compare projects by applying first-order and second-order stochastic dominance (Copeland et al., 2005). These kinds of computations and comparisons are not available with the NPV criterion. For example answers to such questions as the following can be made: what is the probability that the IRR will exceed $12 \%$ ? What is the probability that the IRR will not fall below $9 \%$ ? What is the maximum IRR that is not exceeded by more than $15 \%$ of the times? What is the minimum IRR that is exceeded by as much as $80 \%$ of the times? Or, what is the value of the IRR such that there is a $25 \%$ chance that the actual IRR would be below it? In addition, comparisons between investments can be made. For example first-order stochastic dominance is applicable to projects with different means and standard deviations of returns. It consists of comparing the cumulative distributions of the returns of the two projects and finding out if one cumulative distribution is always greater than the other. Second-order stochastic dominance is applicable for projects with the same means but different standard deviations of returns. It consists of computing the integral of the difference in the cumulative distributions of returns of the two projects, and finding out whether the cumulated difference between the cumulative distributions is always positive or negative for that matter.

To conclude, an approach relying on a probabilistic IRR rejects as impractical all the pitfalls of the IRR mentioned in the literature. Such pitfalls remain therefore an academic curiosity.

\section{The Model}

There are many ways to account for project uncertainties. This paper builds a model upon uncertainties in future net cash flows. It is assumed that the initial cash outlay $(P V)$ is $\$ 20,000$, and that the project consists of 20 yearly cash flows $(C)$. Such a long maturity should produce normal variates because of the Central Limit Theorem. At the start, the cash flows are taken each to follow independently a uniform distribution with a minimum of 500 and a maximum of 4200 . This implies an average cash flow of 2,350 , i.e. $(500+4200) / 2$, and a variance of cash flows of $1,140,833.33$, i.e. $(4200-500)^{2} / 12$. If $r$ is the internal rate of return, then the following equation is satisfied, where $N$ is the term, taken to be 20 years:

$$
P V=\frac{C}{r}\left(1-(1+r)^{-N}\right) \Rightarrow \frac{C}{P V}=\frac{r}{\left(1-(1+r)^{-N}\right)}=f(r)
$$

According to Hillier (1963) this equation was first established by Grant and Ireson (1960). Taking a Taylor series expansion of $f(r)$ in equation (8) around the average of $r$, i.e. $(\bar{r})$, like in Howard (1971) and in Kim and Reinschmidt (2012), then:

$$
f(r) \approx f(\bar{r})+(r-\bar{r}) *\left(\frac{\partial[f(r)]}{\partial r} \mid r=\bar{r}\right)
$$

Therefore:

$$
E(f(r)) \approx f(\bar{r}), \text { because } E(r-\bar{r})=0
$$

This implies that: 


$$
f(r)-E(f(r)) \approx(r-\bar{r}) *\left(\frac{\partial[f(r)]}{\partial r} \mid r=\bar{r}\right) \Rightarrow[f(r)-E(f(r))]^{2} \approx(r-\bar{r})^{2} *\left(\frac{\partial[f(r)]}{\partial r} \mid r=\bar{r}\right)^{2}
$$

Taking expectations on both sides of the second terms of equations (11), then:

$$
\text { variance }[f(r)] \approx\left(\frac{\partial[f(r)]}{\partial r} \mid r=\bar{r}\right)^{2} * \operatorname{variance}(r)
$$

In turn:

$$
\frac{\partial[f(r)]}{\partial r}=\frac{1}{1-(1+r)^{-N}}+\frac{r^{*} N *(1+r)^{-N-1}}{\left(1-(1+r)^{-N}\right)^{2}}
$$

Since $\bar{r}=10.0195 \% \quad$ (See Table 1 ), and $N=20$ then:

$$
\left(\frac{\partial[f(r)]}{\partial r} \mid r=\bar{r}=0.100195\right)=1.5456233
$$

Because variancce $[f(r)]=$ variance $\left(\frac{C}{P V}\right)=\frac{(4200-500)^{2}}{12 *(20,000)^{2}}$

then variance $(r) \approx 0.001193864$ and $\sigma(r) \approx 3.455234 \%$.

This compares with an average standard deviation of $1.699 \%$ (See Table 1). The expected standard deviation is more than twice the actual standard deviation from the Monte Carlo simulation, and the expected variance is more than fourfold the actual variance from the simulation. This is evidence that the Monte Carlo simulations give a more precise estimate of the standard deviation of the IRR. If the variance of the cash flows is doubled the expected standard deviation of the IRR will be $4.88644 \%$. This compares with an actual average standard deviation of $2.4198 \%$ (See Table 1). And finally, if the variance of these cash flows is divided by 2 , then the expected standard deviation of the IRR is $2.44322 \%$. This compares with an average standard deviation of $1.1967 \%$ (See Table 1). In these two cases precision is also enhanced by the simulation procedure. Since 100 replications are effectuated then the expected standard errors of the IRR are respectively $0.3455234 \%$, $0.488644 \%$, and $0.24432 \%$. The actual standard errors are respectively $0.0574 \%, 0.0776 \%$, and $0.0368 \%$. Therefore Monte Carlo simulation has decreased the standard errors by almost six times and the squares of the standard errors by almost 36 times. This shows that Monte Carlo simulation provides a much more precise estimate of the variability of the IRR. It must be mentioned that the 100 replications apply to the case when the investment is divisible and can be selected a hundred times by the same firm or to the case when 100 firms select the same investment.

\section{The Simulation Results}

The procedure followed in this paper is the following. As mentioned in the previous section different probability distributions are assumed. All have the same means. The first and second distributions have the same variance. The third has double the variance. And the fourth has half of the initial variance. Monte Carlo simulation is carried out by generating 10,000 values of the twenty yearly uncertain cash flows, by calculating 10,000 IRRs, and by repeating the procedure one hundred times. A Jarque-Bera test, Jarque and Bera (1987), is applied on each simulation run out of the 100 , and the frequency by which the marginal significance level of $5 \%$ exceeds the actual p-value is recorded for the 10,000 IRRs. For the four distributions this frequency is $4,16,20$, and 10 respectively. There is some evidence that the lower the assumed variance of the cash flows the lower the number of rejections of the normality test. Generally speaking it can be concluded that the 10,000 generated IRRs are close to a normal distribution. This is especially true and surprising for the case when the cash flows follow the uniform distribution.

Table 1 presents the statistics on the repeated simulation runs. Obviously the size of the data is 100 . The grand means are very close to each other and vary between 0.10037 and 0.10053 , and are close to the IRR obtained by taking the expected levels of the cash flows, and which is $10.00504 \%$. Then t-tests for the difference between the latter mean IRR and the grand means of the 4 distributions are conducted. The t-statistics are respectively $0.43136,0.251916,0.61804$, and 0.23533 , all denoting statistical insignificance. Therefore the mean IRR and 
the four grand means are not statistically different from each other. In addition t-tests for the difference in grand means are calculated for each pair of distributions. Table 3 presents the results. The highest t-statistic, in absolute value, is 0.45760 , which denotes insignificance at conventional marginal significance levels. This implies that the grand means are also insignificantly different from each other. Moreover, as shown in Table 1, all grand means are normally distributed according to the Jarque-Bera normality test, the lowest actual p-value being 0.184332 , except for the uniform distribution which has a p-value of 0.003302 , denoting a departure from normality. However the hypothesis of normality for the additional four normality tests in Table 2 fails to be rejected for all 4 distributions. This is to be expected from the Central Limit Theorem. Therefore the rejection of normality by the Jarque-Bera test for the uniform distribution is not consequential. The 100 grand means for the 4 distributions do not exceed 0.102566 and do not fall below 0.098986 . The range is therefore only 0.00358 . Hence the degree of precision is quite high. Tables 1 and 2 show that the 5 normality tests selected fail to reject normality of the 100 standard deviations and the 100 variances, the minimum p-value being 0.0482 . For each distribution the mean standard deviation is very close to the square root of the mean variance. However the distributions of the maxima and the minima seem to be non-normal: 29 tests out of 40 have p-values less than $5 \%$. As a matter of fact there is no reason for these distributions to be normal.

Table 1 descriptive statistics on the distributions within the sample of the 100 repetitions of the 10,000 simulation runs. The sample size is therefore 100 for all statistics. The distributions of the yearly cash flows are given in row 1 , columns 2 to 4 . The initial cash outlay is $\$ 20,000$. The number of periods is 20 .

Table 1. Descriptive statistics on the distributions within the sample of the 100 repetitions of the 10,000 simulation runs

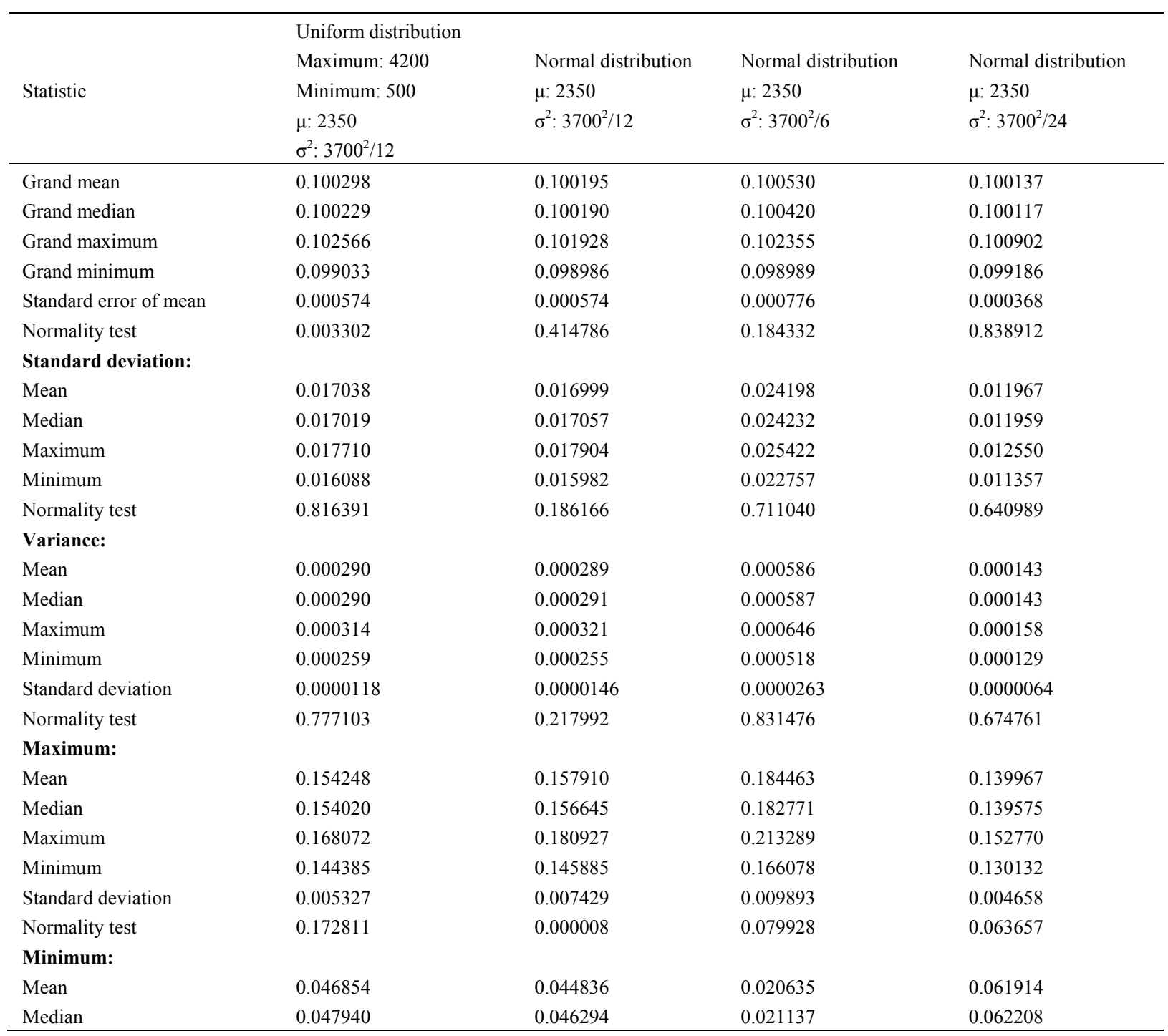




\begin{tabular}{|c|c|c|c|c|}
\hline Maximum & 0.055701 & 0.059426 & 0.040134 & 0.071547 \\
\hline Minimum & 0.028175 & 0.018132 & -0.013460 & 0.046246 \\
\hline Standard deviation & 0.005853 & 0.006835 & 0.010184 & 0.003843 \\
\hline Normality test & 0.000009 & 0.000210 & 0.000238 & 0.000001 \\
\hline
\end{tabular}

Notes: The normality test is the Jarque-Bera test for which the actual p-values are reported. All statistics are obtained with the use of the EViews 8 (2013) statistical software.

Table 2 Tests for normal empirical distributions. Actual p-values are reported. The null hypothesis is a normal distribution. All variables are based on 100 replications of 10,000 simulation runs.

Table 2. Tests for normal empirical distributions

\begin{tabular}{|c|c|c|c|c|}
\hline Variable & Lilliefors (D) & $\begin{array}{l}\text { Cramer-von } \\
\text { (W2) }\end{array}$ & Mises Watson (U2) & Anderson-Darling (A2) \\
\hline \multicolumn{5}{|l|}{ Means: } \\
\hline Uniform & $>0.10$ & 0.4866 & 0.4993 & 0.4515 \\
\hline First normal & $>0.10$ & 0.3613 & 0.3783 & 0.4273 \\
\hline Second normal & $>0.10$ & 0.1956 & 0.2748 & 0.1239 \\
\hline Third normal & $>0.10$ & 0.8844 & 0.8669 & 0.7802 \\
\hline \multicolumn{5}{|c|}{ Standard deviations: } \\
\hline Uniform & $>0.10$ & 0.5315 & 0.4998 & 0.4954 \\
\hline First normal & 0.0917 & 0.0482 & 0.0516 & 0.0494 \\
\hline Second normal & $>0.10$ & 0.6817 & 0.6795 & 0.8088 \\
\hline Third normal & $>0.10$ & 0.8365 & 0.8215 & 0.7745 \\
\hline \multicolumn{5}{|l|}{ Variances: } \\
\hline Uniform & $>0.10$ & 0.4245 & 0.4006 & 0.4082 \\
\hline First normal & $>0.10$ & 0.0764 & 0.0788 & 0.0781 \\
\hline Second normal & $>0.10$ & 0.7680 & 0.7481 & 0.8844 \\
\hline Third normal & $>0.10$ & 0.8477 & 0.8238 & 0.8228 \\
\hline \multicolumn{5}{|l|}{ Maxima: } \\
\hline Uniform & $>0.10$ & 0.2305 & 0.3232 & 0.2081 \\
\hline First normal & 0.0002 & 0.0000 & 0.0001 & 0.0000 \\
\hline Second normal & 0.0298 & 0.0098 & 0.0146 & 0.0132 \\
\hline Third normal & $>0.10$ & 0.0451 & 0.0880 & 0.0229 \\
\hline \multicolumn{5}{|l|}{ Minima: } \\
\hline Uniform & 0.0042 & 0.0004 & 0.0015 & 0.0001 \\
\hline First normal & 0.0150 & 0.0060 & 0.0101 & 0.0068 \\
\hline Second normal & $>0.10$ & 0.0374 & 0.1042 & 0.0056 \\
\hline Third normal & 0.0083 & 0.0023 & 0.0022 & 0.0033 \\
\hline
\end{tabular}

Notes: The uniform distribution is based upon the following parameters: Maximum $=4200$, Minimum $=500, \mu=2350$, and $\sigma^{2}=3700^{2} / 12$. The first normal distribution is based upon the following parameters: $\mu=2350$ and $\sigma^{2}=3700^{2} / 12$. The second normal distribution is based upon the following parameters: $\mu=2350$ and $\sigma^{2}=3700^{2} / 6$. The third normal distribution is based upon the following parameters: $\mu=2350$ and $\sigma^{2}=3700^{2} / 24$. All statistics are obtained with the use of the EViews 8 (2013) statistical software.

Table 3 Hypothesis tests of the equality of grand means. The numbers inside the table are for the absolute t-statistics. The null hypothesis is equality of grand means. The tests assume unequal standard errors. All sample averages are means of 100 replications of 10,000 simulation runs. 
Table 3. Hypothesis tests of the equality of grand means

\begin{tabular}{llll}
\hline & $\begin{array}{l}\text { The first } \\
\text { normal distribution }\end{array}$ & $\begin{array}{l}\text { The second } \\
\text { normal distribution }\end{array}$ & $\begin{array}{l}\text { The third } \\
\text { normal distribution }\end{array}$ \\
\hline $\begin{array}{l}\text { Uniform } \\
\text { distribution }\end{array}$ & 0.12689 & 0.24036 & 0.23613 \\
$\begin{array}{l}\text { The first normal } \\
\text { distribution }\end{array}$ & & 0.34707 & 0.08507 \\
$\begin{array}{l}\text { The second normal } \\
\text { distribution }\end{array}$ & & 0.45760 \\
\hline
\end{tabular}

F-tests that the mean variances of the first two distributions, half the mean variance of the third distribution, and double the mean variance of the fourth distribution are equal to each other are conducted pair-wise. The results are in Table 4, which shows that the minimum p-value is 0.1133 . Therefore the null of equality fails to be rejected. This implies that the simulations keep variances proportional to the assumed variances of the cash flows.

A joint hypothesis test that the squares of the standard errors of the first two distributions, half the square of the standard error of the third distribution, and double the square of the standard error of the fourth distribution are all equal to each other fails also to be rejected. The tests of equality of variances have the following $p$-values: 0.7298 (Bartlett test), 0.8136 (Levene test), and 0.8487 (Brown-Forsythe test). This also implies that the simulations keep standard errors proportional to the assumed standard deviations of the cash flows.

Table 4 is Hypothesis tests of the equality of variances. The numbers inside the table are for the upper-tailed p-values of the F-tests. The null hypothesis is equality of variances.

Table 4. Hypothesis tests of the equality of variances

\begin{tabular}{llll}
\hline & $\begin{array}{l}\text { The first } \\
\text { normal distribution }\end{array}$ & $\begin{array}{l}\text { The second } \\
\text { normal distribution }\end{array}$ & $\begin{array}{l}\text { The third } \\
\text { normal distribution }\end{array}$ \\
\hline $\begin{array}{l}\text { Uniform } \\
\text { distribution }\end{array}$ & 0.4314 & 0.3034 & 0.2437 \\
$\begin{array}{l}\text { The first normal } \\
\text { distribution }\end{array}$ & 0.2460 & 0.3009 \\
$\begin{array}{l}\text { The second normal } \\
\text { distribution }\end{array}$ & & 0.1133 \\
\hline
\end{tabular}

Notes: See notes under Table 2. The mean variance of the second normal distribution is divided by 2 , and the mean variance of the third normal distribution is multiplied by 2 . The test is for the null hypothesis that the ratios of variances, taken two at a time, are equal to 1 . The software MegaStat is used to compute the p-values.

Finally, Table 5 presents the results of undertaking feasibility tests on the IRRs. The probability of the IRR exceeding a certain percentage $(Z)$ is calculated for all three normal distributions. For the first normal distribution this probability is calculated as follows, with $\Phi$ defined as in equation (3):

$$
\text { Probability }(\operatorname{IRR}>Z)=1-\Phi\left(\frac{Z-0.100195}{0.016999}\right)
$$

For the second normal distribution the p-values are obtained as follows:

$$
\text { Probability }(\text { IRR }>Z)=1-\Phi\left(\frac{Z-0.100530}{0.024198}\right)
$$

And for the third normal distribution the p-values obey the following:

$$
\text { Probability }(\operatorname{IRR}>Z)=1-\Phi\left(\frac{Z-0.100137}{0.011967}\right)
$$

For example, the probabilities that the IRR exceeds $9 \%$ are $0.7256,0.6683$, and 0.8015 respectively for the three distributions. And the probabilities that the IRR exceeds $11 \%$ are respectively $0.2820,0.3478$, and 0.2049 . 
Table 5. Upper-tail probability levels for the IRR

\begin{tabular}{llll}
\hline Probability that & The first normal distribution & The second normal distribution & The third normal distribution \\
\hline IRR $>2 \%$ & 1.0000 & 0.9996 & 1.0000 \\
IRR $>4 \%$ & 0.9998 & 0.9938 & 1.0000 \\
IRR $>6 \%$ & 0.9910 & 0.9530 & 0.9996 \\
IRR $>7 \%$ & 0.9622 & 0.8965 & 0.9941 \\
IRR $>8 \%$ & 0.8826 & 0.8019 & 0.9538 \\
IRR $>9 \%$ & 0.7256 & 0.6683 & 0.8015 \\
IRR $>10 \%$ & 0.5046 & 0.5087 & 0.5045 \\
IRR $>11 \%$ & 0.2820 & 0.3478 & 0.2049 \\
IRR $>12 \%$ & 0.1220 & 0.2105 & 0.0485 \\
IRR $>13 \%$ & 0.0398 & 0.1116 & 0.0063 \\
IRR $>14 \%$ & 0.0096 & 0.0514 & 0.0004 \\
IRR $>15 \%$ & 0.0017 & 0.0205 & 0.0000 \\
IRR $>16 \%$ & 0.0002 & 0.0070 & 0.0000 \\
IRR $>17 \%$ & 0.0000 & 0.0020 & 0.0000 \\
IRR $>18 \%$ & 0.0000 & 0.0005 & 0.0000 \\
\hline
\end{tabular}

Notes: See notes under Table 2. The software MegaStat is used to compute the p-values.

\section{Conclusion}

This paper provides a theoretical overview on the internal rate of return (IRR), on the probabilistic IRR, and presents an illustration based upon both a Taylor series expansion and a Monte Carlo simulation. Four different probability distributions are simulated, one of which is a uniform distribution and the other three are normal distributions. All four distributions assume the same mean cash flow, but differ in variances of cash flows. It is shown that Monte Carlo simulation results in more precision than the theoretical precision expected from the Taylor series expansion. This precision is more than twice in terms of the standard deviations of the IRR, and around six times more in terms of the standard errors of the IRR. The distributions of the internal rate of return follow approximately a normal distribution, and this facilitates project appraisal and risk management. The grand means of the internal rates of returns, for all four cases considered, are statistically insignificantly different from each other, as expected, and they are statistically insignificantly different from the average internal rate of return, obtained by discounting the mean amounts of the cash flows. The standard deviations and the standard errors of the IRR are directly proportional to the standard deviations of the cash flows. Finally, the paper undertakes hypothesis tests on the variances and the squares of the standard errors of the IRR, and describes how one can use the probabilistic IRR to carry out feasibility statements.

\section{References}

Alchian, A. A. (1955). The rate of interest, Fisher's rate of return over cost, and Keynes' internal rate of return. American Economic Review, 45(5), 938-943.

Altshuler, D., \& Magni, C. A. (2012). Why IRR is not the rate of return for your investment: Introducing AIRR to the real estate community. Journal of Real Estate Portfolio Management, 18(2), 219-230.

Brealey, R. A., Myers, S. C., \& Allen, F. (2014). Principles of corporate finance. New York: McGraw-Hill.

Carmichael, D. G., \& Balatbat, M. C. A. (2008). Probabilistic DCF analysis and capital budgeting-A survey. The Engineering Economist, 53, 84-102. http://dx.doi.org/10.1080/00137910701864809

Copeland, T. E., Weston, J. F., \& Shastri, K. (2005). Financial theory and corporate policy. Boston: Pearson, Addison Wesley.

Dean, J. (1954). Measuring the productivity of capital. Harvard Business Review, 21-31.

Fairley, W., \& Jacoby, H. D. (1975). Investment analysis using the probability distribution of the internal rate of return. Management Science, 21(12), 1428-1437. http://dx.doi.org/10.1287/mnsc.21.12.1428

Fisher, I. (1930). The theory of interest. Clifton, NY: August M. Kelley Publishers.

Grant, E. L., \& Ireson, W. G. (1960). Principles of engineering economy (4th ed.). New York: The Ronald Press.

Hertz, D. B. (1964). Risk analysis in capital investment. Harvard Business Review, 159-170. 
Hillier, F. S. (1963). The derivation of probabilistic information for the evaluation of risky investments. Management Science, 9(3), 443-457. http://dx.doi.org/10.1287/mnsc.9.3.443

Hillier, F. S. (1965). Supplement to The derivation of probabilistic information for the evaluation of risky investments. Management Science, 11(3), 485-487. http://dx.doi.org/10.1287/mnsc.11.3.485

Howard, R. A. (1971). Proximal decision analysis. Management Science, 17(9), 507-541. http://dx.doi.org/10.1287/mnsc.17.9.507

Jarque, C. M., \& Bera, A. K. (1987). A test for normality of observations and regression residuals. International Statistical Review, 55(2), 163-172. http://dx.doi.org/10.2307/1403192

Jog, V. M., \& Srivastava, A. K. (1995). Capital budgeting practices in corporate Canada. Financial Practice \& Education, 5(2), 37-43.

Keynes, J. M. (1953). The general theory of employment, interest, and money. San Diego: Harcourt Brace Jovanovich.

Kim, B. C., \& Reinschmidt, K. F. (2012). A second moment approach to probabilistic IRR using Taylor series. The Engineering Economist, 57, 1-9. http://dx.doi.org/10.1080/0013791X.2011.624677

Lorie, J. H., \& Savage, L. J. (1955). Three problems in rationing capital. Journal of Business, 28(4), 229-239. http://dx.doi.org/10.1086/294081

Moshe, B. H., \& Kroll, Y. (2012). The limited relevance of the multiple IRRs. The Engineering Economist, 57, 101-118. http://dx.doi.org/10.1080/0013791X.2012.677113

Ross, S. A., Westerfield, R. W., \& Jaffe, J. (2010). Corporate finance. Boston: McGraw-Hill.

Sarper, H., Palak, G., Chacon, P. R., \& Fraser, J. M. (2010). Probability distribution function of the internal rate of return for short-term projects with some random cash flows and extensions. The Engineering Economist, 55, 350-378. http://dx.doi.org/10.1080/0013791X.2010.524279

Schall, L. D., Sundem, G. L., \& Geijsbeek, W. R. Jr. (1978). Survey and analysis of capital budgeting methods. Journal of Finance, 33(1), 281-287. http://dx.doi.org/10.1111/j.1540-6261.1978.tb03404.x

\section{Copyrights}

Copyright for this article is retained by the author(s), with first publication rights granted to the journal.

This is an open-access article distributed under the terms and conditions of the Creative Commons Attribution license (http://creativecommons.org/licenses/by/3.0/). 